\title{
W. RIO APA: AS TRILHAS DA UTOPIA
}

Cristovão Tezza*

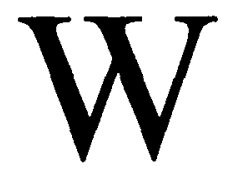

ilson Galvão do Rio Apa, ou simplesmente W. Rio Apa, como assina sua obra, é uma das figuras mais originais da literatura paranaense. Nascido em 1925 em São Paulo, capital, passou a infância e adolescência no Paraná. Na juventude, dedicou-se ao jornalismo e à literatura, formando-se em Direito em 1949 na UFPR. Em seguida, embarcou como marinheiro, viajando pelo mundo durante dois anos. De volta ao Brasil, fixou-se no litoral paranaense, onde, ao lado de uma vida de ilhéu e velejador aventureiro, exerceu intensa atividade jornalística.

Esta primeira fase de sua vida já determina qual seria o perfil do escritor. Ao longo dos anos 50, publicou artigos semanais nos jornais $O$ Estado do Paraná e Última Hora (de São Paulo), em que relatava experiências pessoais de sua vida exótica de marinheiro e ilhéu, entremeadas de reflexões filosóficas. Uma série deles (1951-52) tinha o título de Tentativa de uma grande síntese, o que já nos dá uma medida de seu projeto; outra série (1954), Experiências com a solidão, narrava os trinta dias que passou sozinho numa ilhota do litoral. Mais tarde (1957-58) escreveria semanalmente no jornal A Tribuna, de Santos, relatos de suas viagens num pequeno barco, junto com a família. Esse contato com o mar e com a vida da pesca que marca a biografia de Rio Apa se tornará um dos elementos centrais de sua literatura.

* Universidade Federal do Paraná. 
Desde então, a marca registrada da visão de mundo de W. Rio Apa será entender a atividade artística como parte integrante e inseparável da própria vida; metaforicamente, podemos dizer que seu sonho, desde então, foi fazer da própria existência uma obra de arte. Também desse período - que mereceria uma abordagem mais aprofundada e que aqui apenas resumimos em linhas gerais - podemos extrair alguns pressupostos filosóficos que vão aparecer ao longo de todo o seu trabalho. Um deles, o mais forte talvez, é a idéia rousseauniana do "bom selvagem", que W. Rio Apa desenvolverá de um modo evidentemente não ortodoxo, conciliando-a com um misticismo de traços orientais. Em suma, a natureza tem uma "alma", e todo o seu projeto de escritor será também um projeto ético que nos dê a chave para viver em equilíbrio com ela. Se lembramos que este projeto já se articulava nele, plenamente, nos anos 50, Rio Apa se revela um precursor dos discursos que serão dominantes nas décadas seguintes, dos hippies aos ecológicos.

Também desta primeira fase se afirma outro traço sistemático de seu trabalho: a literatura vai se transformar em bandeira de outras causas que não a de um estrito projeto estético. Frequientemente, o traço efêmero desse trabalho é objetivamente assumido. Nessa perspectiva, compreende-se o caráter na aparência "errático" de sua obra, que do ponto de vista formal foi se construindo aos saltos e desvios, e não por meio de uma lenta elaboração esteticamente unitária. Também daí pode-se compreender a alternância entre a atividade literária e a teatral. Aliás, o teatro vai aparecer na sua vida não como uma forma propriamente literária, mas como algo que realiza a negação da literatura. Seu teatro - que começa a aparecer no final dos anos 60 , fiel ao espírito do periodo - desce dos palcos, vai às ruas e às praças, livra-se do texto fixo e valoriza o improviso; em alguns experimentos, chega a recusar a palavra.

Assim, antes de considerarmos a literatura, vejamos de passagem o teatro de W. Rio Apa, que acompanhei pessoalmente de 1967 a 1984, participando de sua comunidade de teatro em Antonina, litoral do Paraná, e mais tarde em Florianópolis. De sua ampla produção teatral, cujos textos (ou roteiros, no caso de sua última fase) permanecem inéditos, marcamos aqui alguns momentos. O primeiro deles é ainda estritamente literário; trata-se de $O$ pequeno solitário (1968), uma adaptação do conto homônimo incluído na coletânea No mar das vítimas. Nessa peça, todos os elementos convencionais da carpintaria teatral são respeitados, tais como o uso tradicional dos limites do palco, texto fixo, marcações rígidas, preocupação com o acabamento formal, etc. A montagem dessa peça, nos idos conturbados de 68 , teve a marca do tempo: o texto foi primeiramente levado em Antonina, no auditório de um sindicato, com grande sucesso. Em seguida, contando com a voz gravada de 
Paulo Autran (fazendo um personagem que não aparecia em cena), a peça foi montada no Teatro Guaíra, onde se apresentou apenas dois dias. No terceiro, o palco foi fechado com andaimes por ordem do então governador Paulo Pimentel, para impedir a montagem de Navalha na carne, de Plínio Marcos, que seria apresentada a seguir, interrompendo abruptamente a montagem de Rio Apa. Com protestos e uma passeata de que participou uma fatia da classe teatral da cidade, $O$ pequeno solitário foi transferido improvisadamente para um espaço do Diretório Central dos Estudantes, e mais tarde para o então Teatro de Bolso, na praça Rui Barbosa. (Anos mais tarde, a peça seria remontada por Antônio Carlos Kraide e transformada num especial da TV Cultura de São Paulo.)

No ano seguinte, acontece uma ruptura radical: com o Monólogo da violência e o Monólogo da dor e da culpa, Rio Apa descarta não só o texto fixo, mas a própria palavra, propondo um teatro de catarse em contrapartida a uma arte que, limitada racionalmente a um texto escrito, lhe parecia então morta e sem perspectivas. Mais uma vez, estamos diante de um trabalho que se recusa a ser apenas um objeto estético; na verdade, a proposta de Rio Apa supõe uma atitude diante da vida, uma revolução pessoal. O seu teatro sem palavras deveria representar o mergulho do ator em sua realidade subterrânea, digamos assim, para "purificá-lo", retomando o clássico sentido aristotélico sobre a função catártica da tragédia. Abandonando os palcos convencionais, apresenta suas peças em bares e locais públicos de Curitiba e São Paulo - a proposta assumida por ele terá pontos de contato com a teoria do polonês Jerzy Grotowski e seu espetáculo ritual fundado em arquétipos e centrado no ator, que só mais tarde chegaria ao Brasil. O próprio grupo teatral que começa a se consolidar em torno da figura carismática de Rio Apa, numa atividade fervilhante de que tenho viva (e ótima) memória, e que se tomará o Centro Capela de Artes Populares, em Antonina, era na verdade uma comunidade vivendo um projeto existencial do qual o teatro significava apenas uma das faces.

$\mathrm{Na}$ fase imediatamente seguinte, Rio Apa recupera parcialmente o texto, propondo agora um teatro poético de temática popular, mas sempre centralizado na catarse e na liberação emocional. Para ele, esta seria a essência do teatro que cumpria fazer renascer. $O$ teatro deveria ser uma espécie de rito existencial e a comunidade de atores, a realização concreta de uma vida alternativa. Nos anos seguintes, o grupo montou $O$ julgamento do homem (1970), O esperado (1971-1972), Os médiuns (1972) - esta proibida pela censura e liberada a duras penas, somente para festivais, por interferência direta de Paschoal Carlos Magno -, As fúrias (1972), uma recriação de Oréstia, de Ésquilo, e O templo das sete confissōes (1973), peças apresentadas em vários festivais de teatro (Arcozelo, Londrina, São José do Rio Preto, Goiânia, 
Caruaru). Em 1975, com a Paixão de Cristo segundo todos os homens, Rio Apa chega a uma forma de espetáculo total, de fundamento popular, que representa o ponto alto de seu projeto dramático. Desde então, representou anualmente durante a Semana Santa - primeiro em Alexandra, Paraná, e a partir de 1977 nas dunas da Lagoa da Conceição, em Florianópolis - uma Paixão de Cristo por princípio descompromissada de proselitismo religioso, num espetáculo ao ar livre de dois dias que envolve cerca de uma centena de atores e é aberto à participação da platéia. Com o objetivo de eliminar (ou pelo menos suavizar) a fronteira entre a assistência e os atores, o espetáculo aceita desde cenas fixas com diálogos elaborados (mas com ampla margem de improviso e criação própria), até a liberdade de cenas paralelas em meio ao povo, refeições comunitárias, discussões, debates, movimentos de massa, etc. A cada ano, a figura de Cristo ganhava uma face diferente: o revolucionário, o santo popular, o quixote, o poeta, e até mesmo, surpreendentemente, o ateu - Cristo recusando-se a ser Deus em meio a um povo que exige dele esse papel.

Naturalmente, essas montagens eram muito mais do que simplesmente "peças de teatro". O primeiro dado é que quase ninguém da platéia assistia a todo o espetáculo, mas só a partes dele; o público de quinta-feira à noite, por exemplo, que acompanhava as cenas dos profetas do Velho Testamento, nem sempre era o mesmo de sexta-feira pela manhã, com a chegada de João Batista anunciando o Messias. A platéia atingia seu máximo nas cenas da crucificação, no final da tarde de sexta-feira. Outro aspecto a lembrar é o fato de que, à parte dois ou três atores profissionais convidados, todo o resto do elenco era composto de amadores ou mesmo pessoas comuns subitamente envolvidas num projeto de teatro, de acordo com a idéia central de Rio Apa de unir a arte e a vida. É claro que o resultado cênico em muitos momentos não poderia ser julgado com a fria régua do teatro profissional; a Paixão não era exatamente uma peça, mas um acontecimento, ou um happening, para usar uma expressão dos anos 70. Finalmente, a intenção de questionar a figura clássica e acadêmica de Cristo acabava esbarrando na fé popular de parte substancial da platéia: por mais diferente que fosse o sermão da montanha apresentado em cena, o público acabava por ver nele nada mais do que a repetição bíblica, a merecer devoção e não postura crítica. ${ }^{1}$ De fato, não era mesmo intenção do teatro de Rio Apa, desde o início, provocar uma reação racionalizada na platéia; a sua

1 Em 1986, W. Rio Apa publica em parceria com seu filho Thor o álbum de textos e fotos Sermões das dunas, recriando poeticamente os sermões proferidos nas várias apresentações de seu espetáculo. (APA, Thor Rio; APA, W. Rio. Sermões das dunas: a Paixão segundo todos os homens. Florianópolis: Ar Produção \& Comunicação, 1986. 48 p.) 
intenção sempre foi a de criar envolvimento emocional, para ele o cerne do teatro. Daí a proximidade que o teatro de Rio Apa assume, declarada ou veladamente, com práticas terapêuticas, no sentido aristotélico da catarse: purgar as emoções e assim tornar o homem melhor.

O projeto teatral de Rio Apa tem formalmente muitos pontos de contato com a vanguarda daqueles conturbados anos 60 e 70, não só do Brasil como também da Europa, lembrando por exemplo a presença de Grotowski, do Living Theatre (de Julian Beck e Judith Malina) e a influência anterior, mais profunda, de Antonin Artaud (O teatro e o seu duplo). $\mathrm{O}$ abandono do palco italiano, a fragmentação do texto, o despojamento do ator, a idéia da arte como atitude e não como objeto são alguns dos traços que aproximam Rio Apa da linguagem revolucionária daquele tempo. Porém, essa mesma forma transformadora, comum aos movimentos da época, em muitos pontos veiculava uma visão de mundo que pode ser considerada ideologicamente conservadora: a doutrina que se subentende nos "arquétipos" rioapeanos, o trabalho com categorias universais pressupostas (dai sua irresistível atração pela temática religiosa) e um certo toque messiânico são alguns exemplos. Talvez o ponto central esteja na descrença da razão como uma categoria positiva (ou suficiente) de reconhecimento do mundo - também esse aspecto, é verdade, fazia parte da linguagem de combate daqueles anos. Lamentavelmente, entretanto, Rio Apa nunca chegou a formalizar uma "teoria do teatro", uma teoria que só nos resta depreender das próprias realizações e de alguns artigos avulsos que ele escreveu à época. Outro aspecto que limitou o alcance de seu trabalho foi, a um tempo, estar fora do eixo Rio-São Paulo, praticamente exilado em Antonina, e trabalhar rigorosamente com recursos próprios e com um grupo de atores amadores. A comunidade de teatro de Antonina era, afinal, extensão da sua própria casa.

A literatura de W. Rio Apa seguiu uma linha semelhante, no que diz respeito à não-obediência a um padrão convencional, embora nela o rompimento tenha sido muito mais demorado. Seu primeiro texto, cujos originais se perderam, data de seu tempo de estudante: a novela radiofônica Caminho dos deuses. Somente em 1956, quase no fim do seu período jornalístico, aparece seu primeiro romance, Um menino contemplava o rio, início de uma trilogia (Introdução ao Amanhã) que nunca chegou a ser concluída; o segundo volume (O novo Deus), escrito em 1961, permaneceu inédito, e o terceiro ficou apenas no projeto, quando sua literatura tomava outra direção. Seu primeiro livro dá sinais de uma trilha estética da qual Rio Apa logo se afastaria. Romance difícil e de construção sofisticada, entrelaça narrativas num espaço estranho: parte da história passa-se no litoral da Venezuela, e outra numa viagem de navio. A linguagem fragmenta-se em cortes que se destacam graficamente no espaço da 
página; em nota de rodapé, Rio Apa explica que tais recortes têm a intenção de ressaltar "a veracidade e intensidade expressiva da ação subjetiva das personagens". ${ }^{2}$ Eis um exemplo escolhido ao acaso:

O primeiro toque grave, profundo e a sua ressonância surpreendeu o mestiço que começou a acompanhar o badalar:

a sucessão de sons... as vibrações, o balanço dos sinos: as mãos puxando as cordas.

As notas seguiam-se lentas, espaçadas, enchendo-lhe o corpo de vibrações que lhe arrepiavam a epiderme. Momentos depois a alegria mostrava-se no seu rosto. ${ }^{3}$

Depois deste romance, a temática de W. Rio Apa volta-se para o mundo urbano, ou, mais propriamente, contra o mundo urbano, que se lhe afigura como um espaço incompatível com o desenvolvimento das potencialidades criativas do homem. Nesse sentido, sua literatura ganha nesse momento, nitidamente, um caráter de "tese" que jamais a abandonará - é interessante observar que o traço que será a marca registrada de Rio Apa será também o seu limite estético, que afinal (nos anos 90) transbordará para a escrita de textos diretamente místicos e filosóficos. Em 1965 escreveu $A$ proporção correta (inédito), narrando o pânico de uma grande cidade que se vê invadida por animais venenosos, e, em seguida, $A$ revolução dos homens, ${ }^{4}$ romance que conta a história de um lavrador cujas terras são invadidas pela expansão da metrópole, e que, reduzido à miséria, dá origem a um movimento subversivo ecológico (para usar uma palavra de hoje). Visto à distância, $A$ revolução dos homens se inscreve nas inquietações do final dos anos 60 e da instauração da ditadura militar no país. A resposta de Rio Apa, entretanto, tem um substrato romântico e anarquista; a revolução necessária seria não a revolução política de natureza pragmática, mas outra, de "essência". Veja-se este trecho:

De pé, incontrolado, o poeta atingia o paroxismo de sua revolta. Os amigos, preocupados, sondavam a entrada do bar e os

2 APA, W. Rio. Um menino contemplava o rio. São Paulo: Bartyra, 1956. 193 p.

3 Ibid., p. 116.

4 Id., A revolução dos homens. Rio de Janeiro: José Olympio, 1967. 205 p. 
fregueses que esqueciam suas bebidas e ouviam. Queriam interrompê-lo, e não podiam: a mensagem empolgava-os.

- Torpe progresso! Seus sucessos jamais compensarão o estado a que levou o homem! A única salvação reside na consciência de cada um. Temos que continuar caçando, dentro de nós, todos os monstros, prraa! da psicodialética, da despersonalização, prraa! TV, imprensa, prraa! pedagogia utilitária, prraa, prraa! Armindo agachou-se atrás do balcão e prosseguiu no tiroteio visando os produtos enlatados que se enfileiravam nas prateleiras.

- Ou nos tornamos caçadores em nossa própria mente, atirando sem parar com a arma da consciência ou também nós acabamos como os milhōes de zumbis ideológicos russos; sorridentes robôs americanos que disparam bombas atômicas nos seus semelhantes. E são estes dois tipos trágicos que nos querem impingir como modelos ideais do homem moderno. Sejamos brasileiros, isto sim! Bem e profundamente brasileiros, resguardando a matéria-prima que ainda somos, principalmente através desta muito nossa quebra de corpo, esse divino sai pra lá! comigo não, o que é que há? que nos salva da idolatria a tiranos, dogmas, violência, disciplina em excesso c nos mantém na retaguarda do erro progressista. Sejamos assim reservas para a salvação humana, por quanto tempo seja possível e ainda venceremos os atuais deuses fardados com as nossas piadas, gozação como nunca, com a nossa música popular. Viva a África!

As palmas dos fregueses, os bravos de Jeremias, os assobios de Xixo: o poeta foi abraçado, levantado nos ombros.

Num canto, o camponês comovido fungou.

Sucederam-se brindes revolucionários. ${ }^{5}$

Neste trecho curioso encontramos a síntese da crise deflagrada pelo golpe de 64. Era um tempo esquemático: zumbis ideológicos russos, robôs americanos: contra eles, a ginga brasileira. E o valor da "consciência", uma categoria essencial na cosmovisão rioapeana, que parece decorrer não de um processo histórico, mas da própria natureza humana. O progresso "torpe" é o inimigo. A proposta de Rio Apa, oculta nos traços anarquistas, tem uma raiz claramente rousseauniana. Aliás, a revolução de que trata o livro é também uma revolução ecológica, que àquele tempo, na perspectiva do romance, seria o verdadeiro terror do sistema. Se hoje esse projeto parece irremediavelmente

5 APA, A revoluçāo..., p. 157. 
datado, para uma parte da minha geração - e eu me incluo inteiro aí - tinha um apelo irresistível.

Após esse interregno urbano, Rio Apa retorna à temática do mar com No mar das vítimas, ${ }^{6}$ um livro de contos. Esta obra de certa forma marca o seu impasse estético, ou o descompasso entre a sua visão de mundo e a sua linguagem. A temática aqui é rigorosamente a sua: narrando a vida de pescadores isolados do mundo urbano, Rio Apa pode desenvolver e aprofundar a sua visão de mundo mais cara; os pescadores serão a matéria-prima que comprovará sua tese. Entretanto, o descompasso surge pelo fato de que, embora ele domine a técnica romanesca moderna, o que ele provou desde as incursões experimentais de Um menino contemplava o rio, Rio Apa na verdade nunca se sentiu à vontade com a descentralização ideológica que tal prosa supõe. Mais do que na literatura, na verdade ele sempre esteve interessado na doutrina; para ele, a prosa de ficção é claramente um meio de veicular um discurso filosófico unitário, homogêneo e fechado. Assim, em No mar das vítimas, talvez o seu livro "convencional" mais bem-sucedido, encontramos, ao lado dos traços pitorescos de um clássico Brasil rural, pré-urbano, de substância romântica, um narrador atento que não perde o momento de chamar a atenção do leitor para os significados ideológicos daquele mundo. Veja-se, a propósito, o trecho seguinte, do conto "Fandango II", em que o personagem Nato rema desesperadamente para salvar o filho da morte:

\section{Chlan! Chlan!}

- Se o coitadinho morre, juro que faço mais dez filhos!

Chlan!...

Exatamente! A fome e a tua violenta multiplicação. Estas são as tuas invencíveis armas ante as quais os poderosos tremem. $O$ medo crescente aos bilhões de Natos esfaimados que não cessam de gerar filhos incontáveis; ninhadas e ninhadas a chorar e a morrer agora, a exigir ameaçadoramente amanhã a comida que eles não te ensinaram a produzir, e o pouco que primitivamente produzes, roubam-te pelo preço vil que te pagam. Mas não te desesperes, Nato. Tua grande e implacável Mãe já desencadeou a vingança através desse teu procriar desenfreado, inelutável que os apavora, espanta, porque não podem controlá-lo e só poderiam repartindo contigo as riquezas que acumulam. Isto farão somente

6 APA, W. Rio. No mar das vítimas. São Paulo: Brasiliense, 1968. 167 p. 2. ed. Curitiba: CooEditora, 1981. 
à força; a força da tua fome e do teu número espantoso. Oh! eles sabem que dentro de poucos anos, serão os Natos que superlotarão a terra.

Chlan!

Neste conto, o discurso doutrinário reina absoluto, mas do ponto de vista da linguagem No mar das vítimas se insere em geral na melhor tradição do regionalismo brasileiro, no sotaque das expressões, na sintaxe típica, nos traços pitorescos narrados por alguém que não é do meio (o que se denuncia, entre outros sinais, pelo uso sofisticado do mais-que-perfeito) e na boa qualidade do texto. Veja-se:

Comia de tudo a maldita, porém, seu prato predileto era mesmo gente: perna balançando em borda de canoa - o Zeferino manco que conte; braço descuidado, mergulhando demais na hora de recolher o espinhel ou no instante de meter o bicheiro e embarcar a prejereba, como acontecera ao falecido Juvêncio; bêbado que caisse na água, como depois daquele fandango no Superaguy - ninguém mais viu o Calado, só ouviram o baque e, no reflexo da lua, o lombo da desgraça; moça... ah! pobre das moças: "Tem raiva é delas" dizia, sempre, a mais velhinha que passara na juventude o seu grande susto com a "lixeira", numa tarde de noroestado, quando se banhava nas espumas do lagomar."

Independentemente de qualquer outra consideração estética, este livro permanece como uma obra significativa que tem como geografia e pano de fundo o litoral do Paraná, um espaço que aparece sob um registro assumidamente realista.

E é justo nesse momento (1968) que Rio Apa abandona a literatura e passa se dedicar ao teatro, num processo de "desencanto", já que só lhe restava, nas palavras dele, em entrevista a Torrieri Guimarães, "escrever para as elites decadentes, burguesia de leitores cada vez mais escassos".9 Até 1977

7 APA, No mar..., p. 161.

8 lbid., p. 47.

9 Id., Conheça Rio Apa e o seu livro fantástico. Folha da Tarde, São Paulo, 6 out. 1977. Entrevista concedida a Torrieri Guimarães. 
publicou apenas o romance juvenil $O$ menino e o presidente,${ }^{10}$ uma narrativa assumidamente didática, de grande sucesso, que o próprio autor classifica como um acidente na sua carreira de escritor.

É com a tetralogia $O s$ vivos e os mortos ${ }^{11}$ que Rio Apa retorna à literatura, produzindo a sua obra de maturidade e certamente a síntese mais feliz de sua escrita. Neste romanceiro, Rio Apa despoja-se completamente das marcas de linguagem que distanciavam o narrador de seus personagens (no caso do livro de contos) e procura realizar afinal uma arte de raízes para ele autenticamente populares. A tese continua viva: para Rio Apa, "só é grande a arte capaz de ser povo", porque é sempre o povo que "salva e faz renascer a cultura-vida; ele, o povo que ainda está com o pé na terra, nas praias, que é raiz". ${ }^{12}$ Claro que o conceito de povo não é um dado a priori, e simplificá-lo desta forma será uma operação filosoficamente arriscada. Mas estamos ainda no terreno da literatura, e para ela não interessa o ponto de partida; apenas o de chegada. Nesse sentido, como resultado, esta obra é uma guinada em outra direção: Os vivos $e$ os mortos se destaca em muitos aspectos do conjunto dos trabalhos de W. Rio Apa. A linguagem aí faz toda a diferença: não é fácil descobrir o parentesco entre o narrador da tetralogia com o autor de qualquer dos seus outros livros. Podemos dizer que, tomando a língua como referência, Rio Apa "esqueceu" sua própria obra e começou tudo de novo.

Os vivos e os mortos conta a história de um povo, sua grandeza e decadência, num registro literário que incorpora elementos fantásticos e mágicos. Assim, embora haja alguns sinais de que seu espaço seja o do litoral do Paraná, a geografia da narrativa suprime qualquer outra referência espacial que não ela mesma; não caberá aí, portanto, o selo regionalista no sentido comum do termo, porque não se trata de um espaço que se contraponha a outro. Rio Apa debruça-se sobre um mundo que representa um espaço único. Nesse espaço - ou nesse universo - a narração trabalha uma série de histórias entrelaçadas, tendo como eixo dois ciclos: a vida do Santo Menino, contada nos dois primeiros volumes, e a vida do espia Eleé, nos dois últimos. Em torno dessas duas figuras míticas gravitam os personagens principais. Podemos definir a obra como uma narrativa épica, no sentido clássico do termo. Para

10 APA, W. Rio. O menino e o presidente. São Paulo: Brasiliense, 1970.163 p.

11 Id., Os vivos e os mortos. Curitiba: SEEC, 1989. 4 v. v. 1: O povo do mar e dos ventos antigos, 213 p.; v. 2: O santo da ilha na guerra dos rumos, 192 p.; v. 3: O grito do mundo no pássaro cego, 136 p.; v. 4: O último espia na história da fome, 135 p. Os dois primeiros volumes foram editados originalmente pela Editora Brasiliense, em 1977 e 1978.

12 Entrevista citada. 
tornar verossímil este mundo épico hoje, Rio Apa lança mão de um conjunto de recursos de linguagem que irão simular o universo épico com todas as suas necessárias relações ideológicas. Ao lado da geografia única, o tempo na obra representa uma "teogonia", um começo e um fim absolutos; é o tempo inexorável que vem de um passado mítico para um futuro apocalíptico sem propriamente tocar o tempo presente; o passado, na melhor tradição épica, é a expressão da perfeição absoluta; a natureza - mais uma vez encontramos Rousseau - é sempre um valor positivo também absoluto.

Esta visão de mundo perfeitamente articulada se realiza - e aqui a grande originalidade do texto - por uma linguagem que em nenhum momento "abre a guarda" para qualquer traço contemporâneo, moderno ou problemático que pudesse invadir a obra com um ponto de vista ideologicamente conflitante. ${ }^{13}$ Daí a preponderância da ordem direta e da conjunção $e$ (implícita ou explícita); o vocabulário de raiz historicamente popular (há pouquíssimas proparoxítonas no romanceiro - apenas 13 -, que como se sabe são palavras que entraram na língua pelas vias da elite letrada ao longo dos séculos XIV e XV); uma prosa poética que, pelo ritmo e pela própria disposição gráfica, procura envolver o leitor (ou mais apropriadamente o ouvinte) no seu "canto de sereia"; e, o mais surpreendente como recurso retórico de conciliação, a ausência de conjunções adversativas ao longo dos quatro volumes. Para não dizer ausência total, encontram-se cinco expressões adversativas, como só que, expressões a rigor suavizadas.

Por meio desses recursos, a narrativa inteira ganha um estado absoluto de unidade de linguagem, entendida como um ponto de vista soberano sobre o mundo e articulado de um modo que impede a sua quebra, contestação ou fissura por qualquer outra voz. Como ilustração, veja-se o trecho seguinte sobre a "febre do Mal" que assolou a região:
A febre do Mal ficou um pouco mais fraca no povo coa mudan- ça da Lua e do Vento trazendo pra terra o frio do Sul
Também a fraqueza da fome já era tanta que pouca gente saía pras maldades da noite
foi então que as tintureiras subiram a costa procurando as tocas mais quentes do Norte

13 Os vivos e os mortos foi objeto de minha dissertação de mestrado (Os vivos e os mortos, de W. Rio Apa: visão de mundo e linguagem), defendida em 1987, sob orientação do Prof. Dr. Édison José da Costa. No presente artigo retomo de forma bastante resumida alguns pontos desse trabalho. 
e as tainhas seletas apareceram nas barras

Dando graça, os homens se juntaram nas redes, carregaram as canoas e foram pros pontos de espera nas praias de fora enquanto as mulheres se fazendo de santas pegaram as trilhas cos filhos no colo e puxando carrinhos cheios de trastes no caminho cortaram folhas de guareicana, amarraram a palha nas varas e cobriram de novo os ranchos da praia começou aí a espera dura das tainhas do corço de dia atrás das canoas varadas pegando a sombra do Vento de noite junto ás fogueiras esperando o grito do vigia que agüenta sozinho no ponto o frio lá fora

q'nem Aristeu que anda pra cima e pra baixo na praia escutando a fala dos peixes

$\mathrm{Na}$ escuridão o $\mathrm{Mal}$ ainda rondeia ${ }^{14}$

Encerrado o ciclo de Os vivos e os mortos, Rio Apa voltou-se para o ensaio, com o Manifesto do povo, ${ }^{15} \mathrm{em}$ que procura fundamentar o seu conceito de cultura de povo, que ele contrapõe à "cultura urbana". Aqui seu trabalho assume declaradamente um caráter doutrinário, mesmo quando sob forma literária. Publicou então dois outros livros sob a forma gráfica de jornal, ${ }^{16} \mathrm{em}$ que o domínio do estético já não guarda senão pálidas fronteiras com o da filosofia, da biografia, do teatro e da prática existencial, fundindo todos os discursos num só. Sua mensagem central, nesta fase, compreende a idéia inegavelmente fiel ao seu ponto de partida, no início dos anos 50 - de que a cultura urbana chega ao fim, e postula a utopia de uma vida renovada pelo retorno aos valores essenciais da natureza e pelo homem do povo que nela vive integrado. Atualmente, vivendo na Praia da Pinheira, no litoral de Santa Catarina, Rio Apa dedica-se ao ensaio de natureza filosófica. ${ }^{17}$ A epígrafe de seu penúltimo trabalho - "Não é o homem que é sábio. Mas sim a Vida." - já

14 APA, W. Rio. O santo da ilha na guerra dos rumos. p. 71.

15 Id., Manifesto do povo. Curitiba: CooEditora, 1980. v. 1. 136 p. O segundo volume permanece inédito.

16 Id., Depois que as pontes caíram. O amanhã, jomal-livro n. ${ }^{\circ} 1$. Ed. ilust. 24 p. São José: Orleans Gráfica, s/d. e No pico da onda. O amanhã, jornal-livro n. ${ }^{\circ} 2$. Ed. Ilust. 24 p. Florianópolis: Gráfica e Editora Canarinho. 24 p.

17 Id., O saber da vida e da morte. Curitiba: Edições Clandestinas, 1996. 172 p.; Realidade própria. Curitiba: Edições Clandestinas, 1997. 112 p. e A arte em cachorro quente. Curitiba: Ediçōes Clandestinas, $1998.60 \mathrm{p}$. 
nos dá uma pista do caminho atual de sua metafísica. O que é uma outra história, a merecer outro estudo.

Enfim, qualquer que seja a avaliação que se faça do trajeto de W. Rio Apa, dos tempos de marinheiro aos últimos ensaios, o fato é que o conjunto de sua vida e de sua obra e o caráter multifacetado de sua arte jamais perderam de vista um nítido ponto de liga, que é a dimensão da utopia. Para um final de século tão esterilizado de sonhos como este que vivemos, as trilhas seguidas por ele permanecem vivas como um contraponto necessário que tem muito a nos dizer.

\section{RESUMO}

O presente trabalho faz um breve retrospecto da obra teatral e literária do escritor W. Rio Apa, buscando levantar as raízes filosóficas e históricas do seu projeto estético, que sempre entendeu a obra de arte como resultado de uma atitude existencial. No teatro, apresenta-se a identificação de W. Rio Apa com os movimentos de vanguarda surgidos nos anos 60, e na literatura os traços ideológicos doutrinários, de raiz rousseauniana, que marcaram sua ficção.

Palavras-chave: literatura no Paraná, teatro de vanguarda, anos 60 .

\section{ABSTRACT}

This paper presents a brief retrospective of W. Rio Apa's theatrical and literary works. It examines the philosophical and historical roots of his aesthetic experience in light of his view of art as a result of an existential attitude. As a playwright, W. Rio Apa is closely associated with the 1960's vanguard movements while, as a writer, rousseaunian ideology traces have permeated his fictional production.

Key-words: literature in Paraná, vanguard theater, the 1960's. 